\section{Autoantikörper gegen Hitzeschockproteine}

W. Stöcker

Euroimmun Medizinische Labordiagnostika AG, Lübeck, Deutschland

Synonym(e) Anti-HSP-(Auto-)Antikörper

Englischer Begriff heat shock protein antibodies

Definition Autoantikörper gegen verschiedene Zellproteine, die bei Stress (z. B. erhöhter Körpertemperatur) vermehrt exprimiert werden.

Pathophysiologie Möglicherweise spielen Autoantikörper gegen Hitzeschockproteine (Anti-HSP-60) eine ursächliche Rolle bei der Pathogenese der Atherosklerose. Auch bei Autoimmunerkrankungen (rheumatoide Arthritis, chronisch entzündliche Darmerkrankungen) wurden gelegentlich erhöhte Anti-HSP-Titer beschrieben. Ursache könnten hierbei entweder Kreuzreaktionen mit bakteriellem HSP oder vermehrte HSP-Expression der chronisch entzündeten bzw. ge- schädigten Gewebe mit nachfolgender Autoimmunisierung sein.

Untersuchungsmaterial Serum, Plasma.

Analytik $>$ Enzyme-linked Immunosorbent Assay oder - Western blot.

Referenzbereich Autoantikörper gegen Hitzeschockproteine kommen auch bei Gesunden vor. Daher müssen laborspezifische Grenzwerte festgelegt werden.

Bewertung Es gibt derzeit keine gesicherte Indikation für die Bestimmung von Autoantikörpern gegen Hitzeschockproteine.

\section{Literatur}

Grundtmann C, Wick G (2011) The autoimmune concept of atherosclerosis. Curr Opin Lipidol 22(5):327-334

Xu Q, Kiechl S, Mayr M et al (1999) Association of serum antibodies to heat-shock protein 65 with carotid atherosclerosis: clinical significance determined in a follow-up study. Circulation 100:1169-1174 